\title{
La cesación en el oficio por transcurso del tiempo y cumplimiento de la edad prevista
} Loss of Office by Term-Limit or Retirement Age

\author{
Jesús MiÑAMBRES \\ Professore ordinario di Diritto patrimoniale Canonico \\ Pontificia Università della Santa Croce. Facoltà di Diritto Canonico. Roma \\ orcid 0000-0003-0113-1304 \\ minambres@pusc.it
}

Resumen: El reciente motu proprio del papa Francisco Imparare a congedarsi ha vuelto a suscitar interés por los modos de perder los oficios eclesiásticos que se basan sobre el paso del tiempo. El presente estudio, además de presentar las novedades de la norma pontificia, plantea tres problemas hermenéuticos: la diferencia entre la pérdida del oficio por decadencia y los oficios a tiempo determinado; la diferencia entre la decadencia a una determinada edad y la renuncia a esa misma edad; la naturaleza de la intervención de la autoridad en las hipótesis de renuncia y de decadencia.

Palabras clave: Renuncia, Decadencia, Oficio eclesiástico.
Abstract: Pope Francis's recent motu proprio Imparare a congedarsi has prompted renewed interest concerning time-limited ecclesiastical posts. In addition to presenting what is new in the papal norm, this paper addresses three hermeneutical problems: the difference between loss of office due to age and term-limited positions; the difference between retirement and resignation at a given age; and the nature of a competent authority's intervention in cases of resignation and retirement.

Keywords: Resignation, Retirement, Ecclesiastical Office. 


\section{JESÚS MIÑAMBRES}

SUMARIO: 1. El tiempo como factor ordinario para la pérdida del oficio. 2. Pérdida del oficio por transcurso del tiempo y oficios temporales. 3. Oficios a tiempo determinado e indeterminado. 4. Diferencia entre decadencia por edad y obligación de presentar la renuncia. 5. Imparare a congedarsi. 6. Intervención de la autoridad en la decadencia y en la renuncia. 7. Conclusión.

nicio el desarrollo del tema con una advertencia y una cita. La advertencia es que trataré solo aspectos canónicos de la materia de la cesación del oficio. No me ocuparé de las importantes consecuencias civiles que pueden plantearse en estos casos porque su estudio requeriría una acotación de los ordenamientos legales de referencia que no podemos afrontar aquí. La cita es del motu proprio del papa Francisco Imparare a congedarsi, del 12 de febrero de 2018, sobre la renuncia por motivos de edad de los titulares de algunos oficios de nombramiento pontificio, y dice así: «La conclusión de un oficio eclesiástico debe ser considerada parte integrante del servicio mismo, en cuanto requiere una nueva disponibilidad $»^{1}$. Este es, pues, el cuadro en el que me moveré: el ordenamiento canónico en una óptica de servicio.

\section{EL TIEMPO COMO FACTOR ORDINARIO PARA LA PÉRDIDA DEL OFICIO}

El capítulo del Código de Derecho canónico dedicado a la pérdida del oficio eclesiástico ${ }^{2}$ se abre con estas palabras: «El oficio eclesiástico se pierde por transcurso del tiempo prefijado, por cumplimiento de la edad determinada en el derecho, y por renuncia, traslado, remoción ${ }^{3}$ o

1 El texto no ha sido publicado en español (la traducción de la versión italiana es mía): «La conclusione di un ufficio ecclesiale deve essere considerata parte integrante del servizio stesso, in quanto richiede una nuova forma di disponibilità» (http://w2.vatican.va/content/francesco/it/ motu_proprio/documents/papa-francesco-motu-proprio-20180212_imparare-a-congedarsi. html [consultado 25 septiembre 2018]).

2 Capítulo II ( $\ll$ De la pérdida del oficio eclesiástico») del Título IX ( $\ll$ De los oficios eclesiásticos») del Libro I («De las normas generales»).

3 No estudiaremos en esta ocasión la pérdida del oficio por remoción que ha sido actualizada y reforzada recientemente en una norma específica para la remoción de 
privación» (can. $184 \$ 1)$. De este texto se puede deducir que, contrariamente a lo que sucedía en el cuerpo normativo precedente ${ }^{4}$, el legislador entiende que la cesación de la relación entre el oficio y su titular se produce ordinariamente por el hecho de cumplir un determinado periodo de tiempo, ya sea establecido como tal para el desarrollo de sus funciones, ya sea por haber alcanzado una determinada edad. Es decir, la duración de las prestaciones del oficio por parte del titular depende, en la mayor parte de las ocasiones, del hecho del paso del tiempo (el cumplimiento del plazo establecido o de una edad determinada) ${ }^{5}$. Como es sabido, la legislación anterior entendía que la colación de los oficios era, en principio, perpetua y ahí se originaban las distinciones entre oficios (sobre todo el de párroco ${ }^{\circ}$ ) movibles e inamovibles. Incluso durante los trabajos de redacción del Código actual se discutió sobre la "estabilidad" del oficio, distinguiéndola en objetiva y subjetiva ${ }^{7}$, a la hora de acoger la descripción del oficio que ofrecía Presbyterorum ordinis ${ }^{8}$.

En cualquier caso, la relevancia jurídica del cumplimiento del periodo previsto o de la edad establecida, no es automática. Para que estos hechos adquieran relevancia para la pérdida del oficio se requiere la intervención de la autoridad, como señala el can. 186, innovando la materia con respecto a la ley precedente ${ }^{9}$, y estableciendo que «la pérdida

Obispos: Papa Francisco, Carta Ap. Motu Proprio "Come una madre amorevole", 4 de junio de 2016, no publicada en español. Vid. texto italiano en https://w2.vatican.va/ content/francesco/it/apost_letters/documents/papa-francesco_lettera-ap_20160604_ come-una-madre-amorevole.html (consultado el 25-IX-2018).

4 El primer canon del capítulo sobre la pérdida de los oficios eclesiásticos del Código de 1917 comenzaba con la enumeración de los modos en que tal pérdida se produce: «El oficio eclesiástico se pierde por renuncia, privación, remoción, traslación, transcurso del tiempo prefijado» (can. $183 \$ 1$ CIC'17).

5 La dimensión temporal está presente, de alguna manera, en toda relación jurídica.

6 Cfr. can. 454 CIC'17.

7 Para una visión sintética de estas cuestiones, cfr. J. I. ARRIETA, «Oficio eclesiástico», en J. Otaduy - A. Viana - J. SEDANo (coords.), Diccionario General de Derecho canónico (DGDC), V, Aranzadi, Pamplona 2012, 686-693.

8 La descripción que ofrecía del oficio, a propósito del abandono del sistema beneficial, era esta: «ha de entenderse en lo sucesivo cualquier cargo conferido establemente para ejercer un fin espiritual» (ConCIlio VATICANO II, Decr. Presbyterorum ordinis, n. 20).

9 «Il prescritto del can. 186 è nuovo. Nel Codice precedente non esisteva esplicitamente una norma simile» (G. P. MONTINI, Il momento della vacanza di un ufficio conferito per un tempo determinato o fino a una determinata età (can. 186), Quaderni di diritto ecclesiale 9 [1996] 195). 
de un oficio por transcurso del tiempo prefijado o por cumplimiento de la edad solo produce efecto a partir del momento en que la autoridad competente lo notifica por escrito» ${ }^{10}$.

\section{PÉRDIDA DEL OFICIO POR TRANSCURSO DEL TIEMPO Y OFICIOS TEMPORALES}

El contenido de la norma del can. 186, apenas citado, ha suscitado algunas cuestiones interpretativas que afrontamos brevemente. La primera de ellas consiste en aclarar que la "pérdida del oficio" se refiere a la relación jurídica que se establece entre las funciones que lo configuran y su titular -la provisión- y no a la supresión del oficio mismo, que afectaría más bien a la potestad organizativa de la autoridad, es decir, a la relación que surge entre la autoridad y la atribución de determinadas funciones mediante la erección del oficio. Un ejemplo puede ayudar a comprender esta cuestión, bastante obvia, por otra parte. En la organización diocesana se prevé la existencia de varios consejos que ayudan al Obispo. Entre ellos, el Código establece que el Colegio de consultores y el Consejo pastoral se constituyen para un tiempo determinado (cfr. cann. $502 \$ 1$ y $513 \$ 1$ ). La determinación legal implica que, al pasar el tiempo establecido, decae el consejo mismo. En cambio, el oficio del Vicario general es permanente, pero su titularidad decae al cumplirse el tiempo: «Cesa la potestad del Vicario general y del Vicario episcopal al cumplirse el tiempo de su mandato [...]» (can. $481 \$ 1)$.

Para comprender cabalmente la disposición del can. 186 del Código, hay que distinguir, pues, entre la decadencia de la titularidad de las funciones del oficio por edad o por transcurso del tiempo, y la constitución de funciones temporales en la organización eclesiástica. La norma del can. 186 se refiere solo a la titularidad del oficio y no se aplica a la duración determinada de algunos órganos.

\section{Oficios A TIEMPO DETERMINADO E INDETERMINADO}

En el sentido apenas explicado, es posible utilizar las expresiones "a tiempo determinado" y "a tiempo indeterminado" para expresar la

10 Cfr. can. $183 \$ 1$ CIC'17. Cfr. también A. VIANA, Organización del gobierno en la Iglesia, Eunsa, Pamplona 1995, 99-100. 
duración del ejercicio de las funciones del oficio por su titular (y no para referirse a la duración de la determinación de las funciones). Parece útil mencionar brevemente las previsiones legales en este ámbito, ya que evidentemente el legislador ha previsto oficios que siguen atribuidos permanentemente (hasta la muerte del titular o el sobrevenir de otra de las circunstancias que provocan la pérdida de la titularidad de las funciones: privación, traslado, incluso renuncia) y otros que se confieren por un tiempo determinado.

El Código prevé nombramientos por tiempo indefinido en pocos casos, el más conocido de los cuales es el del Romano Pontífice. En realidad, la norma no dice que el oficio sea atribuido por tiempo indefinido, pero la regulación de la renuncia como excepcional ${ }^{11}$ y la referencia a la posibilidad de sede impedida ${ }^{12}$, junto con la ausencia de otras indicaciones expresas y la tradición de la vida de la Iglesia, llevan a la con-

11 Can. $332 \$ 2: \ll$ Si el Romano Pontífice renunciase a su oficio, se requiere para la validez que la renuncia sea libre y se manifieste formalmente, pero no que sea aceptada por nadie».

12 Can. 335: «Al quedar vacante o totalmente impedida la sede romana (...) han de observarse las leyes especiales dadas para estos casos». La ley especial vigente en este momento para estas circunstancias, como es sabido, es la constitución apostólica Universi Dominici Gregis, publicada por san Juan Pablo II el 22 de febrero de 1996 (AAS 88 [1996] 305-343), con las modificaciones aportadas por Benedicto XVI en el motu proprio del 11 de junio de 2007, sobre las mayorías requeridas para la elección. Para mayores profundizaciones sobre este tema, con indicaciones bibliográficas, se puede consultar nuestro comentario a la Universi Dominici Gregis, en J. I. ARRIETA - J. CANOSA - J. MiÑAMBRES, Legislazione sull'organizzazione centrale della Chiesa, Giuffrè, Milano 1997, 1-101. La norma ha sido estudiada desde distintos puntos de vista: cfr., por ejemplo, J. AMMER, Neues im neuen Papstwablgesetz «Universi Dominici Gregis» - ein Kurzkommentar, Folia Theologica 7 (1996) 219-233; J. I. ARRIETA, Il sistema elettorale della cost. ap. Universi Dominici gregis, Ius Ecclesiae 12 (2000) 137-162; G. GHIRLANDA, Accettazione della legittima elezione e consacrazione episcopale del Romano Pontefice secondo la Cost. Ap. Universi Dominici Gregis di Giovanni Paolo II, Periodica 86 (1997) 615-656; I. GRIGIS, La costituzione apostolica Universi Dominici Gregis, Pontificia Università Lateranense, Roma 2004; P. MAJER, «Universi Dominici Gregis». La nueva normativa sobre la elección del Romano Pontifice, Ius Canonicum 36 (1996) 669-712; J. MiÑAMBRES, Il governo della Chiesa durante la vacanza della sede romana e l'elezione del Romano Pontefice, Ius Ecclesiae 8 (1996) 713-729; IDEM, Cambios en las normas sobre el desarrollo del cónclave, Revista General de Derecho canónico y de Derecho eclesiástico del Estado, www.iustel.com, n. 15, octubre 2007; IDEM, Nuove determinazioni sulle capacità decisionali del collegio dei Cardinali riunito in conclave, Ius Ecclesiae 19 (2007) 758-762; L. ORSY, Una scelta per l'unità. Le ragioni di un ritorno alla tradizione per l'elezione del Papa, Il Regno. Attualità 14 (2007) 440-442. 
clusión lógica de que se trata de funciones atribuidas sin limitación temporal alguna, para toda la vida del elegido.

Pero hay también otros oficios que se proveen a tiempo indeterminado: por ejemplo, además del Obispo diocesano, del que nos ocuparemos más adelante, en el derecho universal del Código, a) el Vicario general puede ser nombrado por tiempo indefinido, e igualmente el Vicario episcopal si es Obispo auxiliar (can. $477 \$ 1)^{13}$; b) el párroco debe ser nombrado por tiempo indefinido, salva la excepción prevista en la misma norma (can. 522) ${ }^{14}$, pero se le recomienda que presente su renuncia al oficio a los 75 años (can. $538 \$ 3)^{15}$.

Por lo que se refiere a los oficios cuya provisión a tiempo determinado está prevista por la ley en el Código, se pueden mencionar, por ejemplo, los siguientes: a) los oficios de Vicario general y Vicario episcopal ${ }^{16}$; b) los miembros del consejo de asuntos económicos de la diócesis, en la medida en que esta condición de miembro del consejo pueda ser considerada un verdadero oficio eclesiástico, que se nombran para un periodo de cinco años, renovables ${ }^{17}$; c) el ecónomo diocesano se ha de nombrar para un periodo de cinco años renovables ${ }^{18}$; d) los miembros no ex officio del consejo presbiteral se nombran para un tiem-

13 Can. $477 \$ 1 . \ll$ El Obispo diocesano nombra libremente al Vicario general y al episcopal y puede removerlos también libremente (...); el Vicario episcopal que no sea Obispo auxiliar debe ser nombrado tan solo para un cierto tiempo, que se determinará en el mismo acto de su nombramiento». Como se ve, se trata en este caso de una interpretación del canon que parte del hecho de que se considere excepcional que un vicario episcopal sea nombrado para un tiempo determinado.

14 Can. 522. «El párroco debe tener estabilidad y por tanto debe ser nombrado por tiempo indefinido; solo puede ser nombrado por el Obispo diocesano para un tiempo determinado, si este modo de proceder ha sido admitido, mediante decreto, por la Conferencia Episcopal».

15 Can. $538 \$ 3$. «Al párroco, una vez cumplidos los setenta y cinco años de edad, se le ruega que presente la renuncia al Obispo diocesano (...)».

16 Así se deduce del texto del can. 481 \1, que se sitúa en el contexto de la cesación de la potestad y no en el de la provisión del oficio: «Cesa la potestad del Vicario general y del Vicario episcopal al cumplirse el tiempo de su mandato [...]».

17 Can. 492 \$2: «Los miembros del consejo de asuntos económicos se nombran para un periodo de cinco años, pero, transcurrido ese tiempo, puede renovarse el nombramiento para otros quinquenios».

18 Can. 494 \$ $2: \ll$ Se ha de nombrar al ecónomo para cinco años, pero el nombramiento puede renovarse por otros quinquenios, incluso más de una vez, al vencer el plazo (...)». 
po determinado en los estatutos ${ }^{19}$; e) el arcipreste debe nombrarse para un tiempo determinado por el derecho particular ${ }^{20}$; f) en principio, los Superiores de los institutos religiosos deben nombrarse para un tiempo determinado ${ }^{21}$; g) el Vicario judicial, los adjuntos y los demás jueces de la diócesis deben nombrarse para un tiempo determinado ${ }^{22}$.

Como decíamos antes, también el párroco puede ser nombrado para tiempo determinado si así ha sido establecido por decreto de la Conferencia Episcopal ${ }^{23}$. Algunas Conferencias Episcopales han emanado decretos en este sentido, por ejemplo, la española ${ }^{24}$, la italiana ${ }^{25}$, la francesa ${ }^{26}$, la portuguesa ${ }^{27}$, etc.

19 Can. $501 \S 1$ : «Los miembros del consejo presbiteral se deben nombrar para el tiempo determinado en los estatutos, de manera, sin embargo, que todo el consejo o parte de él se renueve cada cinco años».

20 Can. $554 \$ 2: \ll \mathrm{El}$ arcipreste debe nombrarse para un tiempo determinado, que se concretará en el derecho particular».

21 Can. 624 \$ 1: «Los Superiores han de ser designados por un tiempo determinado y conveniente, según la naturaleza y necesidades del instituto, a no ser que las constituciones establezcan otra cosa por lo que se refiere al Superior general o a los Superiores de una casa autónoma».

22 Can. 1422: «El Vicario judicial, los Vicarios judiciales adjuntos y los demás jueces se nombran para un tiempo determinado $[\ldots]$...

23 Can. 522: «El párroco [...] puede ser nombrado por el Obispo diocesano para un tiempo determinado, si este modo de proceder ha sido admitido, mediante decreto, por la Conferencia Episcopal».

24 «A tenor del can. 522, puede el Obispo diocesano nombrar párrocos para un tiempo determinado, generalmente no inferior a seis años, renovables si así lo exige el bien de las almas. (Nota: Se trata de la facultad que la Conferencia concede a los Obispos para nombrar párrocos ad tempus. De tal facultad puede usar el Obispo cuando así lo considere oportuno, pero no es para él una ley.)» (CONFERENCIA EPISCOPAL ESPAÑola, Decreto general "Sobre las Normas complementaria al Nuevo Código de Derecho canónico", 26 noviembre 1983, Boletín Oficial de la Conferencia Episcopal Española 3 [1984] 95-104).

25 «I Vescovi hanno la facoltà di nominare i parroci "ad certum tempus"» (CEI, decreto del Presidente, 23 dicembre 1983, Notiziario CEI [1983] 209). «Le nomine dei parroci ad certum tempus hanno la durata di nove anni» (CEI, decreto del Presidente, 6 settembre 1984, Notiziario CEI [1984] 204).

26 «Chaque évêque français purra nommer les curés pour six ans avec possibilité de prorogation. (Prorogation veut dire prolongement de durée sans obligation de renouvellement pour une durée égale au premier mandat)» (CONFÉRENCE DES ÉVÊQUES DE France, Decrée 13-VI-1984, Bulletin Officiel de la Conférence des Évêques de France, n. 29, 444).

27 «Em conformidade com a faculdade concedida no cân. 522, a Conferência Episcopal Portuguesa determina que os párocos possan excepcionalmente ser nomeados por um 


\section{DIFERENCIA ENTRE DECADENCIA POR EDAD Y OBLIGACIÓN}

\section{DE PRESENTAR LA RENUNCIA}

La segunda cuestión interpretativa, de las tres que hemos anunciado como suscitadas por el texto del can. 186, se refiere a la distinción entre los casos en que decae el oficio y aquellos otros en que se pide al titular que presente la renuncia. En las leyes universales canónicas es frecuente indicar que los titulares de algunos oficios deben presentar la renuncia a una cierta edad: los Cardenales jefes de dicasterios de la $\mathrm{Cu}-$ ria Romana (can. 354) ${ }^{28}$, los Obispos diocesanos (can. $\left.401 \$ 1\right)^{29}$, los Obispos coadjutores y auxiliares (can. 411) ${ }^{30}$, los párrocos (can. 538 $\$ 3)^{31}$. En todos estos casos, la ley prescribe o recomienda que a una cierta edad se presente la renuncia ${ }^{32}$, pero la pérdida del oficio acaece precisamente por la renuncia, no por haber alcanzado la edad prevista.

periodo não inferior a seis anos a contar da data do decreto de nomeação. Tal nomeação será renovada automaticamente por un novo sexénio e assim sucessivamente, sempre que o Bispo, para o bem das almas, não determinar expressamente o contrário, pelo menos dois meses antes de se perfazer o prazo. A Conferência Episcopal concede faculdade a cada Bispo de nomear os párocos ad tempus; porém o Bispo deve usar tal faculdade, somente quando considerar isto oportuno, não sendo para ele uma lei» (Conferência Episcopal Portuguesa, Decreto do Presidente, 25-V-1985, Lumen [1985] 147-152).

28 «A los Padres Cardenales que están al frente de dicasterios u otros institutos permanentes de la Curia Romana y de la Ciudad del Vaticano se les ruega que, al cumplir setenta y cinco años de edad, presenten la renuncia de su oficio al Romano Pontífice, el cual proveerá, teniendo en cuenta todas las circunstancias» (can. 354). «Al Obispo diocesano que haya cumplido setenta y cinco años de edad se le ruega que presente la renuncia de su oficio al Sumo Pontífice, el cual proveerá teniendo en cuenta todas las circunstancias» (can. $401 \$ 1$ ).

$30 \ll$ Por lo que se refiere a la renuncia del oficio, se aplican al Obispo coadjutor y auxiliar las prescripciones de los cann. 401 y $402 \$ 2 »$ (can. 411).

31 «Al párroco, una vez cumplidos los setenta y cinco años de edad, se le ruega que presente la renuncia al Obispo diocesano, el cual, ponderando todas las circunstancias de la persona y del lugar, decidirá si debe aceptarla o diferirla; el Obispo diocesano ha de proveer a la conveniente sustentación y vivienda de quien renuncie, teniendo en cuenta las normas establecidas por la Conferencia Episcopal» (can. $538 \$ 3)$.

32 El art. 1 del m.p. "Imparare a congedarsi", ya citado y del que nos ocuparemos más adelante, recoge esta misma previsión: «Al compimento dei settantacinque anni di età, i Vescovi diocesani ed eparchiali, e quanti sono loro equiparati dai canoni 381 \$ 2 CIC e 313 CCEO, come pure i Vescovi coadiutori e ausiliari o titolari con speciali incarichi pastorali, sono invitati a presentare al Sommo Pontefice la rinuncia al loro ufficio pastorale». 
En cambio, en otras hipótesis, la legislación canónica prevé la decadencia de la titularidad del oficio al llegar a determinada edad. Quizá el caso más claro era el formulado en el Regolamento Generale della Curia Romana (RGCR) que, al definir las edades límite para la cesación del servicio, distinguía entre lo dispuesto para los Cardenales, que sigue la norma ya citada del can. $354 \mathrm{CIC}$ en la que se les ruega que presenten la renuncia (RGCR, art. $41 \$ 1)^{33}$, y lo previsto para el resto de los titulares de oficios curiales, que terminaban el ejercicio de sus funciones al cumplir una determinada edad: a los 75 años los Arzobispos Presidentes y los Secretarios y equiparados (RGCR, art. $41 \$ 2)^{34}$; a los 80 años los miembros de los diversos organismos (RGCR, art. $41 \$ 3)^{35}$; a los 74 años los Jueces de la Rota Romana (RGCR, art. $41 \$ 4)^{36}$, unificado a 75 años en la Normas propias del Tribunal, de 1994) ${ }^{37}$; a los 70 años los Subsecretarios y equiparados (RGCR, art. $41 \S 5)^{38}$; igualmente los Oficiales, si son sacerdotes o religiosos (RGCR, art. $43 \$ 1)^{39}$; a los 65 años los Oficiales, si son laicos (RGCR, art. $43 \$ 2)^{40}$.

En los casos en los que la edad está prevista como causa de activación de la renuncia y en aquellos en que constituye causa de la cesación en las funciones del oficio, es decir, en las dos hipótesis que estamos estudiando, la decadencia y la renuncia por edad, el can. 185 prevé que pueda «conferirse el título de "emérito" a aquel que ha cesado en un oficio por haber cumplido la edad o por renuncia aceptada». La situa-

$33 \ll(. .$.$) compiuti il settantacinquesimo anno di età sono pregati di presentare le dimis-$ sioni al Romano Pontefice» (art. $41 \$ 1$ ).

$34 \ll$ Gli altri Capi Dicastero, i Segretari e quanti sono ad essi equiparati, compiuto il settantacinquesimo anno di età, decadono dal loro incarico» (art. $41 \$ 2$ ).

$35 \ll 1^{\circ}$ I Membri dei vari Organismi della Curia Romana cessano dal loro ufficio, raggiunto l'ottantesimo anno di età» (art. $41 \S 3)$.

36 «I Prelati Uditori della Rota Romana, secondo le norme proprie, cessano dal servizio attivo al compimento del settantaquattresimo anno di età» (art. $41 \$ 4)$.

37 Norme del Tribunale della Rota Romana, 18 de abril de 1994, art. $3 \$ 2$ : «[i giudici], appena avranno compiuto il settantacinquesimo anno di età, cessano dall'ufficio».

38 «I Sottosegretari ed equiparati sono collocati a riposo al compimento del settantesimo anno di età» (art. $41 \$ 5)$.

$39 \ll$ Gli Officiali sono collocati a riposo al compimento del settantesimo anno di età, se sono chierici o appartenenti agli Istituti di vita consacrata o alle Società di vita apostolica» (art. $43 \$ 1)$.

$40 \ll$ laici, appartenenti ai dieci livelli funzionali, sono collocati a riposo al compimento del sessantacinquesimo anno di età» (art. $43 \$ 2)$. 


\section{JESÚS MIÑAMBRES}

ción del emérito, sobre todo en el caso del oficio episcopal, plantea una serie de cuestiones que no podemos abordar aquí. Para nuestros efectos, baste recordar que se puede producir a partir de la decadencia o la renuncia al oficio por edad.

\section{IMPARARE A CONGEDARSI}

En el número anterior, he usado el pretérito imperfecto al describir las previsiones legales que se refieren a la decadencia de oficios por alcanzar una determinada edad -tanto del Código como del Reglamento de la Curia- porque, como es sabido, el motu propio del papa Francisco del 12 de febrero de 2018 ha cambiado algunas de estas disposiciones $^{41}$. Concretamente, ha pasado a pedir la renuncia a los jefes de dicasterios de la Curia Romana que no sean cardenales, a los prelados superiores de la misma Curia y a los Obispos que ejercen otros oficios dependientes de la Santa Sede, estableciendo que no cesan ipso facto, sino que deben presentar la renuncia ${ }^{42}$. Lo mismo se establece para los representantes pontificios al cumplir los 75 años ${ }^{43}$. Estas renuncias han de ser aceptadas por el Romano Pontífice para adquirir eficacia ${ }^{44}$.

Existen, por tanto, dos tipos de prescripciones legales con respecto al cumplimiento de una determinada edad en relación con el oficio: la que exige o recomienda la presentación de la renuncia, en cuyo caso la pérdida del oficio se produce por la renuncia misma, si no requiere

41 Para un estudio de esta norma, cfr. F. PUIG, Commento alla Leterra Apostolica in forma di "motu proprio" del Sommo Pontefice Francesco "Imparare a congedarsi", Ius Ecclesiae 30 (2018) 647-649; M. GANARIN, Riflessioni a proposito della rinuncia dei Vescovi e dei titolari di nomina pontificia, Revista General de Derecho canónico y Derecho eclesiástico del Estado 47 (2018) 16-18; L. GEROSA, "Imparare a congedarsi": una legge canonica pienamente "pastorale", Veritas et Jus 16 (2018) 87-98.

$42 \ll$ Art. 2. Compiuti i settantacinque anni, i Capi Dicastero della Curia Romana non Cardinali, i Prelati Superiori della Curia Romana e i Vescovi che svolgono altri uffici alle dipendenze della Santa Sede, non cessano ipso facto dal loro ufficio, ma devono presentare la rinuncia al Sommo Pontefice».

43 «Art. 3. Allo stesso modo, i Rappresentanti Pontifici non cessano ipso facto dal loro ufficio al compimento dei settantacinque anni di età, ma in tale circostanza devono presentare la rinuncia al Sommo Pontefice».

44 «Art. 4. Per essere efficace, la rinuncia di cui agli articoli 1-3 dev'essere accettata dal Sommo Pontefice, che deciderà valutando le circostanze concrete». 
aceptación, como sucedió en 2013 con la renuncia de Benedicto XVI ${ }^{45}$, o por la aceptación de la renuncia por parte de la autoridad a la que corresponda (cfr. can. $189 \$ 3$ ); y la que establece la decadencia en las funciones del oficio al alcanzar la edad establecida, caso en el que la pérdida se produce por el cumplimiento de la edad, aunque se requiera la intervención de la autoridad.

\section{INTERVENCIÓN DE LA AUTORIDAD EN LA DECADENCIA Y EN LA RENUNCIA}

Y esta es la tercera cuestión hermenéutica que pone la norma que examinamos, quizá la más difícil y general: cómo se configura la intervención de la autoridad prevista por el can. 186, sin la cual, como ya hemos señalado, el mero transcurso del tiempo o el cumplimiento de la edad no producen el efecto de la cesación del oficio: «solo produce efecto a partir del momento en que la autoridad competente lo notifica por escrito». Como explicó el Secretario de la Comisión que redactó estos cánones, la pérdida del oficio no se produce nunca por "hechos", como el cumplimiento de una determinada edad, sino por la intervención de la autoridad: «cessatio ab officio non venit expletione aetatis sed per auctoritatis actum» ${ }^{46}$. Este acto de la autoridad, requerido sobre todo para evitar interrupciones en el servicio que presta el oficio ${ }^{47}$, es el que lleva a asimilar la decadencia a la renuncia.

En realidad, el hecho de que tenga que intervenir la autoridad en los casos de expiración del plazo o de cumplimiento de la edad, como lo tiene que hacer para aceptar la renuncia, no implica que ambas hipótesis coincidan, como resulta de las consideraciones que ya hemos hecho y de las normas citadas que distinguen entre la decadencia del

45 Sobre esta renuncia, cfr. F. PUIG, La rinuncia di Benedetto XVI all'ufficio primaziale come atto giuridico, Ius Ecclesiae 25 (2013) 797-807; S. VIOLI, La rinuncia di Benedetto XVI. Tra storia, diritto e coscienza, Rivista Teologica di Lugano 18 (2013) 203-214; A. VIANA, Posible regulación de la Sede Apostólica impedida, Ius Canonicum 53 (2013) 547-572; F. LabArGa, La renuncia de Benedicto XVI a la luz de la bistoria, Scripta Theologica 45 (2013) 477-488.

46 Communicationes 23 (1991) 263.

47 Cfr. G. P. Montini, Il momento della vacanza di un ufficio conferito per un tempo determinato o fino a una determinata età (can. 186), Quaderni di diritto ecclesiale 9 (1996) 198-199. 
oficio y la obligación de presentar la renuncia al mismo. Como es obvio, la causa de la pérdida del oficio por renuncia es la renuncia misma aceptada por la autoridad. En cambio, la causa de la decadencia es el paso del tiempo o el cumplimiento de la edad, aunque se requiera la intervención de la autoridad. En el caso de la renuncia, el titular del oficio pide que su voluntad de abandonar las funciones sea aceptada por la autoridad. En los casos de decadencia o de cumplimiento de la edad, el titular del oficio debe advertir de los términos temporales para que la autoridad pueda intervenir. No hay aquí petición sino constatación de un hecho objetivo.

Ciertamente, la autoridad podrá decidir la prórroga de las funciones también en los casos de cumplimiento del plazo o de la edad, pero este acto da un nuevo título al oficial para ejercer el oficio. En cambio, la autoridad que no acepta la renuncia o no responde -según el efecto negativo del silencio administrativo establecido por el can. 57- no atribuye un nuevo título para el ejercicio de las funciones del oficio sino que simplemente no acepta que dicho ejercicio se interrumpa.

Por otro lado, la intervención de la autoridad en los casos de decadencia asegura que quien tiene competencia sobre el oficio conoce su estado de "vacancia" y puede proceder para que se ponga en marcha su provisión (cfr. can. $153 \$ 1$ ). El problema de "interrupción del servicio" podría darse si la autoridad no se activa para notificar la pérdida del oficio a su titular: ¿qué sucede entonces?

El mismo legislador ha previsto que los oficios que se confieren para un tiempo determinado pueden proveerse «dentro de los seis meses anteriores a la terminación de aquel plazo y [la provisión] surte efecto desde el día de la vacación del oficio» (can. $153 \$ 2$ ). Parece que esta norma trata de favorecer la intervención tempestiva de la autoridad para evitar que se produzca la interrupción de que hablamos, sobre todo si se tiene en cuenta la norma general por la que «la provisión de un oficio que, según derecho, no está vacante, es ipso facto inválida, y no se convalida por la vacación subsiguiente» (can. $153 \$ 1$ ). Pero esta posibilidad no garantiza la intervención de la autoridad necesaria para que la decadencia produzca efecto.

Algunos autores han resuelto el problema de la continuidad interpretando que, si lo que hace cesar el oficio es la intervención de la autoridad, el cumplimiento del plazo o de la edad serían solo «motivos que 
la autoridad competente tendrá en cuenta para hacer efectiva o no la pérdida del oficio mediante notificación escrita al titular». Y, por tanto, concluyen: «Si esta no llega, se supone la prórroga tácita del oficio» ${ }^{48}$.

Otros, en vez de hablar de prórroga, prefieren seguir el texto de la ley, interpretando que el cumplimiento del plazo o de la edad establecida «solo produce efecto a partir del momento en que la autoridad competente lo notifica por escrito», es decir, nada cambia en la titularidad, en la posesión o en el ejercicio de las funciones del oficio mientras no se reciba la notificación escrita de la autoridad ${ }^{49}$ : el oficial no puede abandonar las funciones del oficio porque sigue siendo titular de las mismas, y la autoridad no puede proveer el oficio porque no está vacante. Aunque, en realidad, algo cambia; cambia la relación entre el titular del oficio y la autoridad que puede notificar que se han cumplido dichos requisitos. Desde el momento del cumplimiento del plazo o de la edad, el titular ejerce el oficio ad nutum de la autoridad: en el momento en que lo desee, dicha autoridad podrá notificar por escrito el cumplimiento del plazo o de la edad y estos producirán su efecto ${ }^{50}$.

La diferencia entre la prórroga y la continuidad se deduce también del texto del citado motu propio del papa Francisco Imparare a congedarsi, donde se usa el concepto de prórroga en los dos sentidos: «Art. 5. Una volta presentata la rinuncia, l'ufficio di cui agli articoli 1-3 è considerato prorogato fino a quando non sia comunicata all'interessato l'accettazione della rinuncia o la proroga, per un tempo determinato o indeterminato, contrariamente a quanto in termini generali stabilisco-

48 P. GEFAELL, comentario al can. 186, en Á. MARZOA - J. Miras - R. RODRíGUEZ-OCAÑA (eds.) Comentario exegético al Código de Derecho canónico, Eunsa, Pamplona 1996, vol. I, 1045; cfr. también P. V. PinTo, Comentario al c. 186, en P. V. PINTO (cur.), Commento al Codice di Diritto Canonico, Urbaniana University Press, Roma 1985.

$49 \ll(. .$.$) nulla muta nella titolarità, nel possesso e nell'esercizio dell'ufficio né oggettiva-$ mente né soggettivamente tra la scadenza temporale prevista o il raggiungimento dell'età determinata e l'intimazione scritta da parte dell'autorità competente» (G. P. MoNTINI, Il momento della vacanza di un ufficio conferito per un tempo determinato o fino a una determinata età [can. 186], Quaderni di diritto ecclesiale 9 [1996] 200). Cfr. también C. REDAELLI, commento al can. 186, en REDAZIONE DI "QUADERNI DI DIRITTO ECCLESIALE" (cur.), Codice di Diritto canonico commentato, Ancora, Milano 2001, 208.

50 Cfr. G. P. Montini, Il momento della vacanza di un ufficio conferito per un tempo determinato o fino a una determinata età (can. 186), Quaderni di diritto ecclesiale 9 (1996) 200-201. 


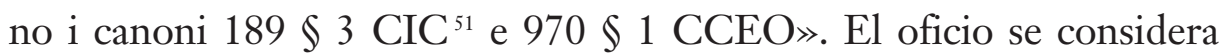
"prorrogado" hasta que se comunique la aceptación de la renuncia o la "prórroga" del oficio. En este sentido, la nueva norma del motu proprio modifica los términos de la ley general del Código en relación a los oficios a los que se aplica: Obispos diocesanos y eparquiales y los equiparados por los cann. $381 \$ 2$ CIC y 313 CCEO; Obispos coadjutores y auxiliares, y los Obispos titulares con encargos pastorales especiales; jefes de dicasterios de la Curia Romana que no sean cardenales; Prelados superiores de la Curia Romana y otros Obispos que desarrollan oficios dependientes de la Santa Sede; representantes pontificios. Para los demás oficios sigue en vigor la norma general del can. $189 \$ 3$.

Aunque las diferencias entre los efectos de la prórroga prevista por unos y los de la continuidad prevista por los otros sean muy semejantes, la opción por la continuidad garantiza que no se pueda pensar que el cumplimiento del plazo disminuya en algo la titularidad de las funciones del oficio. Es frecuente que la prórroga administrativa de funciones imponga limitaciones o reducciones en el ejercicio de las mismas (solo para las cuestiones ordinarias, o solo para lo que no pueda retrasarse, o solo con la intervención preventiva de alguna autoridad, etc.); en cambio aquí se ha querido proteger la continuidad total de las funciones, sin límites. Por otro lado, se podría defender que la transformación que produce el hecho del cumplimiento de los plazos en la relación entre autoridad y titular de algún modo transforma el oficio mismo, lo acerca a los parámetros propios de la potestad delegada alejándolo de los característicos de la ordinaria. Se relativiza el ejercicio del oficio a la voluntad de la autoridad.

\section{ConClusión}

La relación de servicio que se concreta en el ejercicio de un oficio eclesiástico, como todas las relaciones humanas, se da en una dimensión temporal. Los oficios a tiempo determinado son cada vez más frecuentes en la legislación de la Iglesia. Establecer con precisión el momento

$51 \ll$ 3. No produce efecto alguno la renuncia que necesita aceptación, si no es aceptada en el plazo de tres meses; la que no necesita aceptación produce su efecto mediante la notificación del renunciante, hecha según norma del derecho». 
en que quedan vacantes es parte necesaria del buen gobierno que, en la Iglesia, repercute inmediatamente en el bien de las almas.

Por otra parte, la ampliación general de la duración de la vida afecta también a la relación jurídica entre el titular de unas funciones y el oficio que con ellas se constituye. Es prudente contar con la sabiduría y la experiencia de los ancianos; pero también es necesario progresar. La legislación canónica conoce pocos oficios vitalicios, pero cada vez encuentra más necesidad de regular el final de una relación de servicio por el cumplimiento de una edad: que la vacancia se produzca automáticamente o que se prefiera que el titular presente la renuncia es cuestión prudencial que cambia según muchos factores. La tendencia más reciente parece preferir la invitación a la renuncia que la vacación automática del oficio. 


\section{JESÚS MIÑAMBRES}

\section{Bibliografía}

Ammer, J., Neues im neuen Papstwablgesetz «Universi Dominici Gregis» - ein Kurzkommentar, Folia Theologica 7 (1996) 219-233.

Arrieta, J. I., Diritto dell'organizzazione ecclesiastica, Giuffrè, Milano 1997.

- Il sistema elettorale della cost. ap. Universi Dominici gregis, Ius Ecclesiae 12 (2000) 137-162.

-, Oficio eclesiástico, en J. Otaduy - A. Viana - J. SEdano (coords.), Diccionario General de Derecho canónico (DGDC), V, Aranzadi, Pamplona 2012, 686-693.

BENEDICTO XVI, motu proprio del 11 de junio de 2007, http://w2.vatican.va/ content/benedict-xvi/la/motu_proprio/documents/hf_benxvi_motu-proprio_20070611_de-electione.html (consultado 25-IX2018).

ConfÉrence des Évêques de France, Decrée 13-VI-1984, Bulletin Officiel de la Conférence des Évêques de France, n. 29, 444.

Conferencia Episcopal Española, Decreto general "Sobre las Normas complementaria al Nuevo Código de Derecho canónico", 26 noviembre 1983, Boletín Oficial de la Conferencia Episcopal Española 3 (1984) 95-104.

Conferência Episcopal Portuguesa, Decreto do Presidente, 25-V1985, Lumen (1985) 147-152.

Conferenza Episcopale Italiana, decreto del Presidente, 23 dicembre 1983, Notiziario CEI (1983) 209.

—, decreto del Presidente, 6 settembre 1984, Notiziario CEI (1984) 204.

GANARIN, M., Riflessioni a proposito della rinuncia dei Vescovi e dei titolari di nomina pontificia, Revista General de Derecho canónico y Derecho eclesiástico del Estado 47 (2018) 16-18.

García Martín, J. - GallucCi, N., Uffici ecclesiastici conferiti a tempo determinato, con particolare riferimento ai superiori religiosi, Commentarium pro religiosis et missionariis 90 (2009) 257-283.

GeFaEll, P., comentario al can. 186, en Á. MARZOA - J. MiRAS - R. RoDRÍGUEZ-OCAÑa (eds.), Comentario exegético al Código de Derecho canónico, Eunsa, Pamplona 1996, vol. I, 1045. 
GEROSA, L., "Imparare a congedarsi": una legge canonica pienamente "pastorale", Veritas et Jus 16 (2018) 87-98.

Ghirlanda, G., Accettazione della legittima elezione e consacrazione episcopale del Romano Pontefice Secondo la Cost. Ap. Universi Dominici Gregis di Giovanni Paolo II, Periodica 86 (1997) 615-656.

Grigis, I., La costituzione apostolica Universi Dominici Gregis, Pontificia Università Lateranense, Roma 2004.

JuAn Pablo II, Universi Dominici Gregis, 22 de febrero de 1996, AAS 88 (1996) 305-343.

Labarga, F., La renuncia de Benedicto XVI a la luz de la bistoria, Scripta Theologica 45 (2013) 477-488.

MAJER, P., «Universi Dominici Gregis». La nueva normativa sobre la elección del Romano Pontífice, Ius Canonicum 36 (1996) 669-712.

MiÑAMBRES, J., Il governo della Chiesa durante la vacanza della sede romana e l'elezione del Romano Pontefice, Ius Ecclesiae 8 (1996) 713-729.

-, Comentarios a los Títulos X (Prescripción) y XI (Cómputo del tiempo) del Libro I del CIC, en Á. MARZOA - J. Miras - R. RODRÍGUEZ-OCAÑA (eds.), Comentario exegético al Código de Derecho canónico, I, Eunsa, Pamplona 1996, 1091-1115.

-, Universi Dominici Gregis, en J. I. ARrieta - J. CANOSA - J. MiÑAMBRES, Legislazione sull'organizzazione centrale della Chiesa, Giuffrè, Milano 1997, 1-101.

-, Problemi relativi al computo dei termini nei ricorsi contro gli atti amministrativi canonici, en E. BAURA - J. CANOSA (cur.), La giustizia nell'attività amministrativa della Chiesa: il contenzioso amministrativo, Giuffrè, Milano 2006, 483-492.

-, Cambios en las normas sobre el desarrollo del cónclave, Revista General de Derecho canónico y de Derecho eclesiástico del Estado, www.iustel.com, n. 15, octubre 2007.

—, Nuove determinazioni sulle capacità decisionali del collegio dei Cardinali riunito in conclave, Ius Ecclesiae 19 (2007) 758-762.

MontiNI, G. P., Il momento della vacanza di un ufficio conferito per un tempo determinato o fino a una determinata età (can. 186), Quaderni di diritto ecclesiale 9 (1996) 195-208. 
ORSY, L., Una scelta per l'unità. Le ragioni di un ritorno alla tradizione per l'elezione del Papa, Il Regno. Attualità 14/2007, 440-442.

Papa Francisco, Carta Ap. Motu Proprio "Come una madre amorevole", 4 de junio de 2016, https://w2.vatican.va/content/francesco/it/ apost_letters/documents/papa-francesco_lettera-ap_20160604_come-una-madre-amorevole.html (consultado 25-IX-2018).

—, Motu proprio "Imparare a congedarsi", 12 de febrero de 2018, http: //w2.vatican.va/content/francesco/it/motu_proprio/documents/papa-francesco-motu-proprio-20180212_imparare-a-congedarsi.html (consultado 25-IX-2018).

PINTO, P. V., Comentario al c. 186, en P. V. PINTO (cur.), Commento al Codice di Diritto Canonico, Urbaniana University Press, Roma 1985.

PUIG, F., La rinuncia di Benedetto XVI all'ufficio primaziale come atto giuridico, Ius Ecclesiae 25 (2013) 797-807.

-, Commento alla Leterra Apostolica in forma di "motu proprio" del Sommo Pontefice Francesco "Imparare a congedarsi”, Ius Ecclesiae 30 (2018) 647-649.

Redaelli, C., Commento al can. 186, en Redazione di "Quaderni Di DIRITTO ECClesiale" (cur.), Codice di Diritto canonico commentato, Ancora, Milano 2001.

Tribunal de la Rota Romana, Normas, 18 de abril de 1994, AAS 86 (1994) 508-540.

VIANA, A., Organización del gobierno en la Iglesia, Eunsa, Pamplona 1995.

—, Posible regulación de la Sede Apostólica impedida, Ius Canonicum 53 (2013) 547-572.

VIOLI, S., La rinuncia di Benedetto XVI. Tra storia, diritto e coscienza, Rivista Teologica di Lugano 18 (2013) 203-221. 